\title{
GEOGRAFÍA, HISTORIA Y LENGUA
}

\author{
Geography, history and language
}

\author{
Francisco Abad Nebot ${ }^{1}$ \\ Recibido: 23/01/2012 Aceptado: 30/03/2013
}

A la memoria de Julián Alonso, compañero durante más de treinta años en las Facultades de Filosofía y Letras de Valladolid y de la UNED

Resumen. Hablamos de la incidencia geográfica en la historia; de la "Iarga duración"; de geografía lingüistica y sociolingüistica. El geógrafo mira un paisaje y se esfuerza por explicarlo, ciertamente muchas veces el lugar geográfico puede estar situado fuera del contexto histórico, de hecho en algunos lugares se puede hablar otro idioma y pertenecer administrativamente a otro lugar o pais distinto, especialmente en los espacios de frontera en donde las decisiones políticas pueden pesar que las tradiciones y costumbres. La geografía e historia se unen indisociablemente y siempre le acompaña el lenguaje como la forma de expresión de lo geográfico a través de la descripción del paisaje y de lo histórico en base a relatar lo ocurrido, también por supuesto a través de la palabra.

Palabras clave: André Allix; F. Braudel; L. Febvre; geohistoria; larga duración ; Ramón Menéndez Pidal, Hugo Schuchardt; Jaume Vicens Vives.

Abstract. We discussed the geographical incidence in history of "long duration"; linguistic and sociolinguistic geography. The geographer looks at a landscape and strives to explain, certainly many times the geographical location may be located outside the historical context, in fact in some places you can speak another language and administratively belonging to another place or country other, especially in the areas of frontier where policy decisions can weigh the traditions and customs.

The geography and history come together inextricably and always accompanies the language and the form of expression of geographically through description of the landscape and the historic recount based on what happened, also course through the word.

Key words: André Allix; F. Braudel; L. Febvre; geohistory; length; Ramón Menéndez Pidal, Hugo Schuchardt; Jaume Vicens Vives.

\section{ESPACIO Y TIEMPO}

\section{André Allix}

La serie de obras "La evolución de la humanidad" que constituyeron la "Biblioteca de Síntesis Histórica" dirigida por Henri Berr incluyó dos volúmenes paralelos que trataron respectivamente de "La tierra y la evolución humana.
Introducción geográfica a la Historia", y "El lenguaje. Introducción lingüistica a la historia", que estuvieron a cargo de Luciano Febvre (según dice la traducción castellana) el primero, y de J. Vendryes, el discípulo de Meillet, el segundo; ambos textos empezaron a prepararse antes de la guerra del 14, y quedaron publicados tras la contienda.

Estas "Introducciones" revelaban ya la pertinencia de atender lo geográfico y lo histórico en conjunción, y asi-

(') fabad@flog.uned.es. Catedrático de Filologia en la Universidad Nacional de Educación a Distancia. 
mismo las lenguas en relación a la historia y la geografía -el tratado de Vendryes incorpora capítulos sobre geografía y lenguas-.

A estas cuestiones se han referido otros autores asimismo: haremos algunas referencias representativas en la primera y en la segunda parte de estos párrafos.

Georges Duby ha llamado la atención sobre lo inescindible en ocasiones de la Geografía con la Historia, y ha mencionado en este sentido a su maestro el geógrafo bien conocido entre nosotros André Allix; ha escrito el enorme medievalista Duby:

"El geógrafo mira un paisaje y se esfuerza por explicarlo. Sabe que ese objeto, verdadera obra de arte, es el producto de una larga elaboración, que lo ha modelado a través de los tiempos la acción colectiva del grupo social que se instaló en ese espacio y aún hoy sigue transformándolo. Por consiguiente el geógrafo se ve obligado a estudiar antes que nada lo material, es decir, los elementos físicos modelados poco a poco por el grupo social; pero con la misma atención analiza también las fuerzas, los deseos, la configuración de esos deseos y por tanto, se ve obligado a hacerse poco o mucho historiador" (Duby, 1992, p. 11).

Así le ocurrió -concluye nuestro medievalista- a uno de sus maestros, André Allix, quien analizó registros de archivos del siglo XV. De esta manera Georges Duby quedó orientado bajo la dirección de quien fue rector de Lyon "hacia una nueva concepción de la [H]istoria" (Ibid., p. 12; escribimos con mayúscula la Historia en tanto 'historiografia', y con minúscula la historia como 'los hechos acontecidos', 'los hechos empíricos del pasado': seguimos de esta manera la propuesta de José Antonio Maravall).

Según es sabido, André Allix publicó en los años 1937 y 1948 el que vertido a la lengua española fue su Manual de Geografía General. Física, Humana y Económica; en él, cuando sienta los principios de la Geografía humana, establece de manera más implícita de como lo hará después su discipulo Duby, pero de modo inequívoco, las vinculaciones de lo geográfico con lo histórico. Establecía ya Allix -en efecto- la traza en que iban a desenvolverse sus discípulos: "La Geografía humana -escribió- estudia en primer lugar las relaciones que existen entre el hombre y el escenario de su vida, [...] entre las sociedades humanas y el paisaje geográfico que las circunda" (Allix, 1960, p. 312), concepción que incide de manera clara según decimos en nuestro historiador medievalista. Y añade todavía Allix en el mismo sentido: "La Geografía humana trata de deslindar exactamente la parte de la naturaleza y de la civilización en la vida de los hombres y en la composición del paisaje" (Ibid.).

El análisis de los paisajes da lugar a "el ejercicio más interesante de la ciencia geográfica", siempre que se entienda que ese análisis ha de tener presentes los componentes que se asocian y combinan en un paisaje geográfico, a saber: "estructura física, tectónica, subsuelo, relieve, efectos del clima sobre la vegetación y las aguas, estructura agraria, plano catastral, repartición de los árboles, de los campos, de las casas, de los caminos" (Allix, 1960, p. 326).

$Y$ por igual hace alusión nuestro autor -aunque sin emplear estas denominaciones- a la toponimia y la coronimia: de esta manera cabe saber que "el nombre de una región o de un país, evoca a la vez particularidades físicas y tradiciones humanas". A. Allix define además la idea de "país" en tanto "un dominio geográfico que presenta cierta unidad, con una comunidad de origen en las condiciones humanas: poblamiento, lengua, tradiciones, historia, géneros de vida, economía regional'; corónimos de estos "países" son en Francia "Normandia", "Provenza", ... (Allix, ibid.); en el caso peninsular un "país" resultaría Cataluña, y por igual la misma España, o Portugal.

\section{Braudel}

El mismo Georges Duby nos confiesa cómo admiraba a Braudel, y "consideraba El Mediterráneo y el mundo mediterráneo [en la época de Felipe II] como uno de los grandes libros de historia que se han escrito en este siglo [XX...] Obra espléndida, modelo [, libro que] se puede seguir recorriéndolo inagotablemente" (Duby, 1992, p. 116); antes, en 1950, L. Febvre había escrito que si se lee el trabajo de Braudel "on admire chemin faisant la perfection d'un travail fait de main d'ouvrier, l'abondance et la qualité des matériaux mis en ouvre, la richesse d'une imagination sans faille. [...] Parfait ouvrage" (1982, p. 168).

Este obra egregia requiere en verdad que se la lea (o relea) por sí misma y entera, mas cabe aludir mínimamente a la "Primera Parte" del libro, un libro por sí mismo que va -en la versión castellana- de la página 25 a la 468. Dos observaciones que hace el autor las recogemos asi:

A) "Por lo común la montaña es un mundo [...] marginal, situado a extramuros de las civilizaciones, que son producto de las ciudades y de las tierras Ilanas. Su historia consiste en no tenerla [...]. Para estos mundos encaramados, sin contacto con las ciudades, ni la misma Roma, a pesar de la pasmosa duración de su poderío, significó gran cosa, a no ser por los campamentos de las legiones que para su propia seguridad establecía el Imperio en los bordes mismos de estas moles insumidas; así surgió por ejemplo León, al pie de los montes cantábricos". Y añade aún Fernand Braudel en nota a pie: "En la Bética, Roma tuvo éxito en la región baja, a lo largo de los ríos, mucho más que en los altiplanos [...]. En el Noroeste montañoso de España, debido además a la lejanía, Roma penetró tarde y mal" (Braudel, 1976, I, p. 40; sobre "el primado de las Ilanuras: Andalucía", se extiende el autor en sus pp. 104-109).

Nuestro autor insistirá en los mismos hechos a propósito de la latinización idiomática, y de esta manera expone asimismo: "Por la misma razón, el latín no llegó a prevalecer 
como lengua en parte alguna de estos macizos hostiles del norte de África y de las Españas, y la casa latina tuvo siempre su asiento en las tierras Ilanas. Fuera de algunas infiltraciones locales, no tuvo nunca acceso a la montaña" (lbid., p. 41).

Efectivamente Menéndez Pidal tiene escrito (pero sus páginas no las pudo conocer el historiador francés) cómo la expansión romana en la Península se inició por el levante y el sur, desde Cataluña "hasta las bocas del Guadalquivir", y de esta manera la latinización se produjo según "ondas propagadoras [...] de Sureste a Noroeste": el Noroeste conserva menos inscripciones y entre ellas "las más rudas y vulgares", mientras las de levante y sur son más en cantidad y más correctas en el idioma; entre las ciudades de ese Noroeste enumera don Ramón las que se corresponden con las actuales León, Braga o Astorga (Menéndez Pidal, 2005, I, pp. 91-95 y 161-164). Según vemos, las observaciones pidalinas y las de Braudel resultan en líneas generales convergentes y complementarias.

B) Fernand Braudel define asimismo las "altas llanuras" o "mesetas", las cuales son 'grandes y altas Ilanuras descubiertas, de suelo seco -en el Mediterráneo al menos-, y por consiguiente duro, con raros tajos fluviales'. El más bello ejemplo de las mesetas lo encuentra el autor a mitad de los años cuarenta en que escribe, en "las dos Castillas"; de unos pasajes que han de leerse en su totalidad escogemos estas líneas:

Estos interminables convoyes de bestias de carga [atraviesan] las Castillas de norte a sur y de sur a norte según el calendario de los pastos. Descendiendo hacia el sur en el invierno, subiendo hacia el norte en el estio, transportan todo lo que se ofrece a su paso: trigo y sal, lana y madera, cerámica o loza de Talavera, mercaderías y viajeros. [...] Este movimiento de acarreo es el que permite a Castilla servir de nexo de unión entre las regiones periféricas de la Península que la rodean y la separan a menudo del mar. Es ese tráfico y no Castilla como se ha dicho, lo que ha hecho a España (Braudel, 1976, pp. 66-69, subrayado por nosotros).

Quienes mantuvieron cómo Castilla había hecho a España fueron Ortega y Gasset, y de manera más implícita Menéndez Pidal; ahora Braudel declara las rutas comerciales, el mercado, en tanto fundamento activo de la constitución social-histórica de España. Menéndez Pidal insistió a su vez en la expansión de la lengua castellana, aunque debe matizársele que al inicio de esa expansión ocurrió más como idioma escrito y literario que como lengua hablada ordinaria.

\section{Las duraciones en el tiempo: la anticipación de Menéndez Pidal}

La tentativa de geohistoria llevada a cabo de manera magistral por Fernand Braudel iba a conducirle a teorizar también sobre las duraciones largas en la historia, y a establecer una tipología de las diversas duraciones que se producen en lo histórico: no es lo mismo una larga pervivencia que un hecho concreto que se da en un momento también determinado, etc.

De unos años más tarde que El Mediterráneo... es el escrito de nuestro autor que trataba de "La larga duración", el cual distinguía la existencia de un "tiempo corto": "existe un tiempo corto de todas las formas de la vida" (para lo que sigue de Braudel, 1968, pp. 60-106). En la diacronía lingüística la verdad es que tal tiempo corto apenas si lo comprobamos; si acaso, hay innovaciones léxicas o fraseológicas que alcanzan una duración más o menos efímera. El "tiempo corto" no es un atributo de la naturaleza del lenguaje, que es densamente tardigrado en su evolución, y asi se mueve y recorre su trayectoria de rasgos de manera lenta, sobre todo por lo que se refiere al idioma hablado común.

Se da en lo histórico en general -señalaba además nuestro autor- "oscilaciones cíclicas": en la trayectoria del lenguaje podemos considerar por nuestra parte que esos ciclos responden a épocas de duración media, por ej., la época de Juan Ruiz y del príncipe don Juan Manuel en la historia del castellano, o la de Cervantes, o la del primer tercio del siglo XX, etc. Existe así "un recitativo [...] que para estudiar al pasado lo divide en amplias secciones: decenas, veintenas o cincuentenas de años". Traído a lo idiomático, creemos decididamente -al modo pidalino- que cada etapa o época discernible analíticamente en el pasado de la lengua debe ser de unos treinta años o un tercio de siglo, si bien es verdad que don Ramón llegó a abandonar un tanto el designio de esta tripartición temporal de cada centuria.

Fernand Braudel asimismo delimitaba una historia "de amplitud secular": se trata (apostillaba) "de la historia de larga, incluso de muy larga duración". Señalaba además el historiador francés cómo "la palabra estructura [...] domina los problemas de larga duración", aunque ciertamente cabe decir asimismo que a veces las duraciones medias constituyen por igual "estructuras" de lo histórico general.

Dice muy bien Braudel que "la historia es la suma de todas las historias posibles", y así ocurre con la historia lingüistica: han de tenerse presentes a la vez el tiempo corto -el de una innovación léxica efímera-, el tiempo de la media duración que proponemos se considere en el alrededor de un tercio de siglo, y el tiempo de las largas duraciones; el único error -dice nuestro autor- [...] radicaría en escoger una de estas historias a expensas de las demás". Con F. Braudel -parafraseando un enunciado suyo-, debe postularse también que la Historia de la lengua es la suma de todas sus historias posibles, la suma de sus cortas, medias y largas duraciones.

Toda historia (política, de la ciencia, económica, del arte, etc.) presenta una articulación temporal interna; Menéndez Pidal aludió a esa consistencia interior en los párrafos primeros de su divulgado artículo "El lenguaje del siglo XVI", y en uno $u$ otros escritos vino a distinguir asimismo -antes de Braudel (lo que no se ha observado), aunque en coincidencia con él- las tres clases de duración histórica; los siguien- 
tes pasajes pidalinos que citamos proceden de $R$. Menéndez Pidal, 1933.

"Concebimos tan cómodamente la historia dividida en siglos -ilustraba el maestro gallego-asturiano- que casi no podemos hacer otra división, sobre todo tratándose del lenguaje, cuya evolución conocemos sólo a grandes rasgos. Se trataba pues de poner en juego el más ajustado positivismo analítico, de llenar cualquier Historia de la lengua de contenido empírico, precisando todos los hechos que se pudiese y precisándolos cronológicamente; las lenguas se desarrollan según una geografía y cronología (según una sociología también), y esto no cabe desconocerlo al historiarlas.

Comprobado el uso de las divisiones temporales por centurias, Menéndez Pidal abogaba contrariamente en su escrito del año 33 por buscar segmentos de tiempo mejor articulados y que respondiesen de manera específica a cada realidad del pasado, que alcanzasen así mayor adecuación en lo empírico.

Sin embargo -manifestaba nuestro autor-, para articular razonablemente cualquier exposición histórica, el primer cuidado, creo, debe ser el de quebrar ese mecánico y descomunal molde [del siglo] para ver cómo la materia en él encerrada se nos presenta dividida en otras porciones, cuajadas por sí mismas.

Se trata de desechar una mera exposición de lo histórico por siglos, amplitud que el maestro califica de "descomunal" ('enorme'), y de buscar por contra segmentos temporales cuajados internamente en sí mismos, es decir, delimitaciones de duración media que respondan a lo empírico de lo real y que intenten interpretarlo y traducirlo. Menéndez Pidal aboga por la articulación de cada centuria en varias secuencias temporales de caracteres individuales precisos, que son aquellas de las que el estudioso deberá dar cuenta. Ejemplifica incluso nuestro autor con lo que ocurre con el llamado "siglo de oro" de las letras españolas, atendido a veces en tanto una unicidad que se prolongaba -según se suele decir- de Garcilaso a Calderón, cuando en verdad no pueden mezclarse los tiempos del Emperador Carlos con los de los Felipes, ni estos entre sí. "Y aun, a menudo (exclamaba sorprendido don Ramón), la centena suele parecer poco, y se habla de los siglos XVI y XVII mezcladamente -los siglos de oro-, confundiendo las direcciones del uno con las del otro".

En fin don Ramón expone el principio que va a guiarle en el análisis que hace ahora, en 1933, del lenguaje del XVI, y enuncia con decisión: "Me propongo indicar someramente una periodización más corta que el siglo, una estimación más precisa del factor temporal que nos pueda encaminar hacia individualidades históricas más reales". En efecto el objeto formal propuesto es el de las individualidades históricas reales, el del pasado en tanto es posible delimitar en él consistencias de peculiaridades propias que se suceden e interpenetran en ocasiones en la línea del tiempo. Toda obra -enfatizó una vez Pierre Vilar- posee una fecha.
De acuerdo con este principio de la duración media, el maestro establece en el siglo XVI de las bellas letras españolas una época de Nebrija (1492-1525), un período de Garcilaso (1526-1554), otra época o período de los grandes místicos (1555-1585), y en fin el período de Cervantes y Lope de Vega (1585-1617), en el que ya "la lengua del Quijote no fué la característica". Estamos en los cuatro casos ante sendas individualidades históricas cronológicas, con consistencia filológica propia y caracterizables por sí mismas: en tiempos de Garcilaso se escribia con claridad elocutiva y libertad en los contenidos; en los de Lope ha escrito ya también sus obras mayores Luis de Góngora y ha puesto en práctica por tanto la poética de la oscuridad en tanto factor estético; etc.

No obstante el propio maestro Menéndez Pidal había teorizado también y seguiría teorizando en otros textos suyos distintos del que acabamos de ver, acerca de la "enorme lentitud en el desarrollo y propagación de un cambio lingüístico", esto es, acerca de procesos de muy larga duración. Estamos en efecto ante el hecho de que la constitución (entiéndase 'propagación y vigencia') de la ley fonética es obra de un lapso de tiempo muy prolongado. Los idiomas resultan ser productos muy fuerte o densamente tradicionales, y así toda innovación lingüistica encuentra una resistencia grande en tal masa tradicional constituida por modos de elocución, y sólo se propaga mediante una gran duración -al menos hasta ahora en que la televisión resulta un vehículo propagador casi instantáneo-. Ocurren por tanto en el idioma duraciones incluso multiseculares, y este es un dato de sus duraciones internas.

En la vida del lenguaje coexisten así tanto procesos de duración media (las Ilamadas épocas del idioma, sus períodos) y otros de larga duración (generalización de una ley fonética, etc.); desde luego pueden advertirse a veces hechos más o menos instantáneos, como fue el de la rápida vigencia de la palabra golfo en el hablar madrileño de fines del siglo XIX, según atestiguó por su parte el propio Menéndez Pidal al escribir en 1900: "En cuanto á golfo, golfa, que hace unos 10 ó 12 años se usa en Madrid para denotar "pilluelo, vagabundo", parece una resurrección de la voz golfín desprovista de su sufijo diminutivo"; la fórmula verbal "deterioro cognitivo" estaba sólo en boca de los especialistas, pero en la misma Madrid y desde hace unos tres o cuatro lustros no deja de oírse algunas veces en conversaciones ordinarias en las que se habla de nuestros mayores.

\section{SOBRE LA "GEOHISTORIA"}

Como se sabe Jaume Vicens Vives se interesó en los años cuarenta por los asuntos geopolíticos y escribió entre otras cosas una obra de conjunto: Tratado general de geopolítica, que cabe ver (antes, y por ej., cfr. Febvre, 1982, pp. 130-138). 
El autor delimita por ej. la "Geografía histórica" de la "Geohistoria", y define así la primera: "Geografía histórica es la rama de la geografía humana que se ocupa del examen estático de las relaciones del hombre con el suelo que habita, en un pasado más o menos remoto. En este aspecto, suministra material de primer orden [...] sobre todo a la Geohistoria", disciplina esta última que efectivamente consiste en "la ciencia geográfica de las sociedades históricas organizadas sobre el espacio natural", y que -concreta Vicens- "afín por su contenido a la Geografía histórica, se diferencia de ella por su sujeto -la sociedad cultural-, y por el método -el dinamismo geopolítico-" (Vicens, 1950a, pp. 79-80); en este sentido El Mediterráneo... es una obra geohístórica según queda dicho, imcluso más de lo que estimaba el historiador catalán.

En un manual de bachillerato del mismo año, nuestro autor define entonces: "La Geohistoria es una ciencia que intenta averiguar la influencia de los elementos geográficos (clima, situación natural, relieve, hidrografía, etc.) en los acontecimientos históricos, y particularmente en el nacimiento y desarrollo, poderío y decadencia de los Estados)" (Vicens, 1950b, p. 4; la definición se recoge también en Vicens, 1956, p. 214).

Vicens se movía en la traza de Toynbee, aunque procuró no caer en el determinismo, y de ahí que mantuviese que el poder creador en la historia reside "en la capacidad del espíritu social para hacer frente a los sucesivos estímulos internos y externos que se le presentan", ya que el hombre -los hombres y las mujeres- se conquista a sí mismo "por un proceso de autodeterminación espiritual" (Vicens, 1950a, p. 95). El creer en el determinismo supone "un gravísimo peligro intelectual" -abunda el autor-, dado que el espíritu humano "puede o no puede doblegarse ante el medio geográfico" (1950b, p.5; obsérvese el error sintáctico: debía haberse escrito que el espíritu humano "puede o puede no doblegarse...").

No obstante la advertencia para que no se caiga en concepciones deterministas, Vicens mantuvo en lo concreto cómo por entonces "la supremacía política, técnica y espiritual corresponde a aquellos pueblos que se hallan situados en zonas de grandes contrastes climatológicos", ya que la adversidad natural se hacía de esta manera "formidable acicate" de las creaciones del hombre (1950a, p. 107). En otro momento enunciará el autor que son las situaciones históricas (las "circunstancias", escribe él), las que tienen la última palabra en cuanto a la valoración de los accidentes geográficos naturales (lbid., p. 123).

De otra parte nuestro autor aludió al hecho general del mecanismo histórico de tendencias unificadoras y también corrientes autonomistas, y lo ejemplifica con Italia y Alemana, para mencionar asimismo el caso peninsular de vaivén que se registra en la historia de España (tribus primitivas, centralización romana, cantonalismo bárbaro, unificación visigoda, Califato de Al-Andalus, reinos de Taifas, parcelamiento político cristiano, unificación nacional, Juntas de la Guerra de la Independencia, etc. (1950a, pp. 112-113).
Se advertirá que la referencia que se hace a 1479 (aunque sin nombrarlo asi) no debe ser propiamente a una unificación nacional, sino a la unidad estrictamente dinástica: Isabel no reinó en Aragón, y Navarra era por entonces reino aparte.

Otra consideración geohistórica puede hacerse a propósito de los pasos de los Pirineos, que en cuanto tales han resultado "puertas de invasión" entre Francia y España y en ambos sentidos, y que han unido regiones como CataluñaRosellón, y a los navarro-vascos (1950a, p. 119, y para Cataluña y tales pasos, pp. 124-125; complétese sobre Francia con Vicens, 1950b, capítulo 31).

En fin Jaume Vicens define la situación geohistórica de la Península, la cual se caracteriza "por determinar sobre su territorio una cruz, cuyas aspas están formadas por dos corrientes geohistóricas: la mediterráneo-atlántica de Este a Oeste, y la euroafricana de Norte a Sur".

Tal situación geográfica "ha procurado a los pueblos peninsulares importantes coyunturas históricas, y asimismo lo ha significado dentro del grupo de la Cultura Occidental con características propias" (1950a, pp. 127-128; con variaciones véase en Vicens, 1956, p. 294, en un epígrafe que ahora se denomina "Valor geopolítico de España").

Consideraciones geohistóricas aparecen en el planteamiento hecho hace poco por el historiador y asimismo estudioso de la astronomía José Luis Comellas. Él se refiere por ej. a cómo las centurias del XIV al XVIII -señala una veztendieron más al frío que las anteriores y las posteriores a ellas: se trató de esta manera de un largo período frío, de una edad fría de aproximadamente 1450 a 1850 (Comellas, 2011, pp. 190-191 y ss.); de hecho y en relación al XVII ya se había hablado por varios autores (Domínguez Ortiz, etc.) de estas cosas. Nuestro autor incluye ilustraciones como estas, a saber:

La pequeña edad del hielo [...] realmente existió [...En las regiones del sur de España] alternaron los fríos con lluvias torrenciales. En Córdoba se registraron hasta once riadas del Guadalquivir en el siglo XVII, frente a solo dos en el XVI, cinco en el XVIII, dos en el XIX y otras dos en el XX. En Sevilla las riadas no solo fueron frecuentes sino desastrosas. En 1626 la avenida duró dos meses, y quedaron inundadas 8.000 casas; otras riadas famosas se produjeron en 1635, 1646, 1658, y ocho consecutivas en el invierno 1683-84, "en que se temió el fin del mundo". También el frío alcanzó niveles no recordados: nevó en Sevilla el 3 de enero de 1622, el 31 de enero de 1634 , en que también se helaron las fuentes, y en 1641 heló el 20 de abril. Lo mismo ocurrió en abril de 1649, en que hizo "un frío como en enero" [... "Semanas después"] se desencadenó la peste [...] En el siglo XVII y en momentos del XVIII y hasta mediados del XIX hubo episodios de fríos terribles (Comellas, 2011, pp. 203-207; en general sobre las ofensivas del frío y de la muerte en el Seiscientos, p. 208). 
Comellas postula que se busque la intercausación de los factores de un cambio climático, y postula por igual prudencia cuando se extraigan consecuencias históricas de los acaeceres climáticos: escapa así del determinismo, pero no rechaza lo geohistórico: "Insinuar (escribe) que un determinado proceso climatológico fue "una de las posibles causas" -ien modo alguno la única!- de un hecho histórico, no tiene por qué ser un disparate" (Ibid., p. 216). Etc.

Otra monografía con un componente geohistórico fue en su día la de José Alcalá-Zamora (1975; vid antes su artículo 1970). A orografía, clima, hidrografía, etc., españolas, se refieren los tratados de Estructura económica también: Velarde, 1969; Tamames, 1969.

\section{LENGUA Y GEOGRAFÍA}

\section{Qué es la Geografía lingüistica}

El mencionado texto de L. Febvre "La tierra y la evolución humana. Introducción geográfica a la Historia" -hecho con el concurso de Lionel Bataillon- hace algunas referencias a lo idiomático y a los lingüistas (Febvre, 1925, pp. 206208). En otro escrito postulará el autor la relevancia de los textos y de sus contenidos semánticos, significativos: "Los textos. Pero se trata de textos humanos. Las mismas palabras que los forman están repletas de sustancia humana.[...] Hay que utilizar los textos, sin duda. Pero todos los textos. $Y$ no solamente los documentos de archivo en favor de los cuales se ha creado un privilegio [...]. También un poema, un cuadro, un drama son para nosotros documentos, testimonios de una historia viva y humana, saturados de pensamiento y de acción en potencia..." (Febvre, 1970, pp. 29-30).

Se trata por tanto de incluir entre las fuentes -junto a las de archivo- a las artísticas y a las literarias; esta proclama del autor francés incidió seguramente en el trabajo historiográfico de José María Jover -quien acostumbraba a mencionarlo en sus clases-, y a través de don José María o directamente desde Febvre, en el trabajo del aludido José Alcalá-Zamora.

La presente referencia a los textos es una referencia a la lengua, a la designación y al significado de las palabras y al sentido de los textos; de hecho y en varios de los capítulos de Pour une Histoire à part entiére, Lucien Febvre trata de "palabras y nociones" o de "palabras e ideas" (vid. su 1982). Vamos a hablar nosotros ahora en varios párrafos de lengua y geografía.

En su momento, lorgu lordan definió la geografía lingüística o geografía dialectal en tanto 'el estudio cartográfico de las hablas populares', y de esta manera ocurre que "un mapa lingüístico es un verdadero cuadro sinóptico de los hechos lingüísticos en su distribución geográfica" (Iordan, 1967, pp. 251254). Con el tiempo, el registro dialectal se ha hecho no sólo de las hablas rurales como al principio, sino por igual de las hablas cultas y del todo de las hablas urbanas; en lengua española el primer autor que subrayó la diferenciación social o diastrática del hablar no fue García de Diego -aunque lo dicen hasta los especialistas: M. Alvar, etc.-, sino el P. Félix Restrepo.

De manera rigurosa como solía escribir, Eugenio Coseriu trazó hace ya un tiempo un panorama de conjunto acerca de qué es y cómo se desarrollaba "La geografía lingüística" (1977, pp. 103-158), y la definió, y estableció también por qué no podia dejar de interesar a las disciplinas geográficas.

El rigor y la claridad del presente escrito del autor rumano hace que deban citarse a la letra dos párrafos suyos completos, que recordamos de nuevo en el presente escrito; empieza como es lógico por definir esa materia, y expone: "La expresión "geografía lingüística" designa exclusivamente un método dialectológico y comparativo [...] que presupone el registro en mapas especiales de un número relativamente elevado de formas lingüísticas (fónicas, léxicas o gramaticales) comprobadas mediante encuesta directa y unitaria en una red de puntos de un territorio, o por lo menos, tiene en cuenta la distribución de las formas en el espacio geográfico correspondiente a la lengua, a las lenguas, a los dialectos o a los hablares estudiados" (Loc. cit., p. 103). Estamos ciertamente ante la representación en un mapa de los hechos idiomáticos que se han obtenido mediante encuesta especifica, hechos que en el caso peninsular e interpretados, dan lugar a comprobaciones sobre el funcionamiento del lenguaje, sobre población y Reconquista, etc.

En segundo lugar advierte Coseriu acerca de la pertinencia para la ciencia geográfica -como decimos- de esta Geografía lingüística, y enuncia así cómo las comprobaciones que establece la materia se relacionan estrechamente con la geografía como tal y no pueden dejar de interesar a esta disciplina -en la medida en que considera la tierra como "habitat" del hombre, y al mismo tiempo, considera como pertenecientes a su objeto todas aquellas realizaciones humanas que tengan extensión en el espacio-, no sólo por el empleo común del instrumento cartográfico, sino también porque revelan un aspecto esencial de las relaciones entre la vida social y cultural del hombre y su ambiente natural (Ibid., pp. 104-105).

La geohistoria acoge por tanto -y según esta concepción- a la Geografía lingüística, y se ocupa o debe ocuparse asimismo del hablar en función del medio natural (las designaciones de las 'colmenas' que se hallan hechas con corcho, según un ejemplo clásico de G. Rohlfs; etc.)

\section{Hugo Schuchardt}

Antes de una afirmación clave de Saussure que vamos a recordar, el relevante Hugo Schuchardt ya había reflexionado hacia fines del Ochocientos sobre la dimensión geográfica y social de las lenguas. Schuchardt insistió en la complejidad 
idiomática entendida como variación, como dialectalidad de las comunidades de habla: el hablar no resulta uniforme según las situaciones elocutivas, ni según las geografías ni la estratificación social; tales variaciones resultan así diatópicas, diastráticas y situacionales (creemos esta voz más transparente que la que suele usarse de diafásica).

Según el relato que de las ideas de Schuchardt nos hace lordan, sucede que en el interior de una misma comunidad del hablar "encontramos innumerables hablas individuales que varían según el sexo, edad, [...] cultura, etc.", hablas que "influyen una sobre otra [...] sin llegar a suprimir las diferencias existentes entre sí [...]: la manera de hablar de las personas influyentes, las que se dice que son reputadas como "superiores" por los otros hablantes, es imitada de manera incontenible", y esto lleva a la mezcla de las diferentes hablas debido a la mencionada imitación, y debido por igual a la movilidad geográfica de los individuos, a su movilidad social, etc.; Alberto Vàrvaro glosa bien que en el presente concepto de "mezcla" entra "cualquier tipo de contacto no sólo entre lengua y lengua, sino también [...] entre individuo e individuo" (Vàrvaro, 1968, p. 118). Y sucederá de esta forma que no existen límites geográficos tajantes entre distintas lenguas 0 dialectos, ni límites cronológicos determinados tampoco en lo diacrónico entre una época del idioma y otra: las isoglosas se interpenetran, se entrecruzan (lordan, 1967, pp. 49-51).

Ciertamente las hablas ordinarias son resultado de una mezcla idiomática, y en general no consisten sino en una variación o dialectalidad interior de hechos comunes y hechos diferenciados, algunos de ellos imitados y que por tanto llevan a una mezcla, al igual que llevan a la mezcla la fusión étnica, ... H. Schuchardt parece entender como una clase de mezcla idiomática la difusión de las innovaciones desde unos hablantes a otros: "existen estilos individuales que con el tiempo y por imitación, se expanden y se convierten en generales" -ya lo hemos visto-; de hecho Ilama a este asunto de la mezcla lingüística el de "más importancia" de la ciencia idiomática, y ciertamente y entendido según él lo hacía, se trata de un asunto que incluye en sí varios otros, y que debe alcanzar gran relieve (lordan, 1967, pp. 81 y 84).

Ocurre en todo caso que las lenguas y los dialectos consisten interiormente en un haz de isoglosas de que se interpenetran y se entrecruzan, y dan lugar así a límites borrosos; según la letra de nuestro autor: "Imaginémonos la lengua en su unidad como una superficie de agua; ésta se pone en movimiento porque en diversos lugares se forman círculos concéntricos, cuyos sistemas más o menos extensos según la intensidad de la fuerza motriz, se entrecruzan" (apud lordan, 1967, p. 82).

Schuchardt proclamaba ya en 1866 que "cualquier cambio lingüístico general procede de un espacio limitado y se difunde lentamente sobre el área lingüística completa" (apud Vàrvaro,1988, p. 77).

Aún en vida de Schuchardt, Saussure mantuvo en la misma traza una afirmación de relieve en su Curso, la cual ha quedado un tanto inadvertida en ese Curso -se halla en la "Cuarta Parte"-: la de que la evolución toma la forma de innovaciones sucesivas y precisas, que constituyen otros tantos hechos parciales, susceptibles de ser enumerados, descritos y clasificados según su naturaleza (hechos fonéticos, lexicológicos, morfológicos, sintácticos, etc.). [...] Al superponerse en el mapa, donde sus límites se entrecruzan, esas áreas forman combinaciones extremadamente complicadas. [...] No hay más que caracteres dialectales [...], no hay dialectos (subrayamos nosotros el presente pasaje que ya hemos recogido en alguna ocasión).

Como decimos Ferdinand de Saussure parece moverse en la traza de Hugo Schuchardt, y halla la feliz fórmula de que no hay dialectos homogéneos (ni lenguas homogéneas), en definitiva, no hay códigos lingüisticos uniformes, sino caracteres lingüísticos, complejidad interior de rasgos que funcionan para la expresión verbal, para la elocución (de y sobre Schuchardt pueden encontrarse materiales en abierto a través del buscador "google").

\section{Pidal y las hablas leonesas}

Hacia los mismos años de fines del Ochocientos y principios del siglo XX inicia la que sería una hercúlea labor filológica Ramón Menéndez Pidal, y una de sus primeras monografías fue una de carácter dialectal: la dedicada a "EI dialecto leonés" (1906; citamos por la reedición de 1962, pero teniendo también a la vista el primitivo texto).

El autor redacta un $§ 1$ en el que trata de los límites de este dialecto latino y así va exponiendo de acuerdo a la vez con la lengua, la historia y la geografía:

a) "Al Oriente, junto al mar, hallaremos algún rasgo leonés hasta Castro Urdiales, uniéndose así al parecer todo Santander a Asturias como un todo lingüístico; no obstante [...] el límite entre los Astures y los Cántabros estaba en el río que Pomponio Mela llama S a I i a y que no puede identificarse fonéticamente sino con el Saja, con lo que sólo el tercio occidental de la actual provincia santanderina habria pertenecido antiguamente a la región asturiana."

b) "La Extremadura leonesa se dividía de la castellana a la muerte de Alfonso VII (1157) por la calzada de Guinea, o sea la vía romana de Mérida a Salamanca. [...] Si Plasencia, al Oriente de la Calzada de Guinea, fué poblada por el rey de Castilla Alfonso VIII, el lenguaje allí implantado sería no leonés por fuerza."

c) "Por el Occidente [...] es preciso ir marcando una línea que pase por entre pueblos vecinos, de los cuales los de Occidente no diptonguen la ŏ y ě latinas", de manera que pronuncian "corpo", "terra", y los de Oriente "cuerpo", "tierra". "En Asturias, junto al mar, el dialecto leonés no empieza sino a la derecha del 
río Navia; [...]el gallego se extiende por una faja de unos ocho kilómetros al oriente del Navia. Probablemente este límite estará determinado por razones históricas tan antiguas, que tendrá algo que ver con el límite de los conventos jurídicos Asturicense y Lucense; el río Navia, según Plinio, separaba a los astures pésicos de los gallegos lucenses."

d) "En la provincia de Zamora el pueblo de Ermisende habla gallego. Pero en cambio entra el dominio del leonés en el reino de Portugal, en Riodonor, Guadramil [...] y además la tierra de Miranda, [...el cual] no es más que uno de tantos restos del leonés occidental. [...] El mirandés diptonga la ŏ y ě latinas, carácter que tomaremos como fundamental en la clasificación de un dialecto como leonés y no como gallego-portugués". Y añade y explica aún Menéndez Pidal:

"El leonesismo del mirandés obedece a razones históricas [... muy] antiguas, pues la tierra de Miranda en la España romana pertenecía no al convento jurídico Bracarense, sino al Asturicense, y en la Alta Edad Media la iglesia de Braganza perteneció a la diócesis de Astorga, hasta que luego se desmembró por la dificultad de pertenecer a un reino diferente. Si la tierra de Miranda era primitivamente una hijuela de Astorga, nada más natural que el dialecto de ambas regiones sea el mismo" (Menéndez Pidal, 1962, el mencionado § 1).

La organización del espacio, el medio natural y lo histórico todo, dan lugar a la distribución lingüística, y así lo analiza don Ramón en esta fecha temprana de 1906; casi desde los inicios de su obra sabe el maestro que lo idiomático ha de analizarse según regiones y épocas, y así lo haria hasta culminar en su texto magno Orígenes del español (1926). Vemos además cómo las fronteras entre hablas se hallan difuminadas, borrosas, entremezcladas -no resultan lineales-, y dependientes en todo caso de la organización administrativa del espacio.

Poco más tarde de los primeros análisis de este último filólogo español, Vendryes escribió el volumen aludido "El lenguaje. Introducción lingüística a la historia", y en él incluye también consideraciones sobre las lenguas y la geografía. Vendryes, tras Schuchardt y tras Saussure y A. Meillet, sabe bien cómo "las particularidades lingüísticas no tienen nunca una misma área de extensión o, en otros términos, que las líneas de isoglosas no coinciden y son independientes unas de otras", aunque no obstante "hay un dialecto definido en el área en la que se observan particularidades comunes" (Vendryes, 1979, pp. 267-269). La lengua es diferenciación interior, mezcla parcial de códigos, entrecruzamiento de isoglosas.
La idea por tanto de que no existen propiamente códigos lingüísticos homogéneos y uniformes, sino rasgos 0 caracteres que dan lugar a las hablas bien sean escritas, dialectales, diastráticas, etc., ha sido mantenida por los autores de esta lista incompleta:

\section{H. Schuchardt.}

Saussure.

Menéndez Pidal (más implícitamente).

Vendryes.

\section{Karl Jaberg}

Podemos mencionar ahora a otro estudioso de relieve posterior a los anteriores, Karl Jaberg (1877-1958). Iordan destaca varios caracteres de sus estudios como lingüista geógrafo, que vamos a recoger según él y para introducirnos:

a) "Partiendo de un concepto (esto es, un mapa), estudia en todos sus aspectos las palabras que sirven para designar aquella noción". Resulta así un estudioso de la onomasiología, y por igual de las palabras y las cosas: cfr. seguidamente c).

b) "Alude a los estadios antiguos o a la situación de los fenómenos en otras lenguas románicas."

c) "Concede la atención que se merece a la historia cultural, siguiendo el método de 'palabras y cosas'", esto es, en una línea que coincide con los postulados de lingüistas como Schuchardt o historiadores como Febvre, si entendemos entre las "cosas" también las 'ideas'. "La lengua como expresión de la cultura y la lengua como medio de comunicación se dan la mano" -expresará Jaberg-.

d) "Se interesó también por el factor psicológico del lenguaje y en qué medida los estados afectivos individuales condicionan las modificaciones lingüisticas" (lordan, 1967, pp. 372-375, y vid. en el índice temático "palabras y cosas").

Karl Jaberg escribió varios textos que a todas luces responden a la propia marcha de los estudios de geografía lingüística, y que resultan instructivos; el primero de ellos es de 1908, y se trata de Geografía lingüística. Ensayo de interpretación del "Atlas Lingüístico de Francia". Estamos ante un comentario acerca de esos autor (Guilliéron) y Atlas pioneros, y nuestro autor glosa:

1. "Jules Gilliéron es quien primero ha emprendido la exposición cartográfica de los fenómenos morfológicos y léxicos, sin limitarse exclusivamente a los fonéticos. En esto descansa la importancia del magnífico [...] ALF" (Jaberg, 1959, p. 11). 
2. "La ley fonética que afirma que un cierto fonema latino bajo ciertas condiciones y en un lugar determinado se mantiene inalterable o evoluciona hacia un determinado fonema nuevo, es una abstracción. En realidad cada palabra tiene su historia particular. Las áreas de la misma evolución fonética, en palabras diferentes, no se superponen exactamente", esto es, que como ha insistido la romanística, no existen las leyes fonéticas tales cuales sino más bien historia particular de las palabras, y que las isoglosas se entrecruzan sobre el terreno. "Cada palabra, lo repito, [...] tiene su historia particular" (Ibid., pp. 20-21; 35). Esto lo dirá también Pidal.

3. "Siempre son las regiones periféricas -mantiene Jaberg en esta fecha temprana- las más conservadoras, y de entre ellas las que políticamente han sido independientes por más tiempo" (lbid., p. 31). Es una afirmación anticipada de lo que postulará la neolingüistica.

4. "Sería sorprendente que siendo París el punto crucial de todos los intereses, la reina espiritual de Francia, no lo fuera también en la vida lingüística. Pero este hecho general no nos exime de la obligación de indagar en cada caso particular los motivos especiales del avance de las palabras francesas". Estamos ante el hecho de la migración de las voces, y enseña Karl Jaberg cómo de una parte las causas del avance de una palabra son positivas: la palabra que avanza posee cualidades que le aseguran su victoria; de otra parte son negativas: ciertas cualidades disminuyen la capacidad de resistencia de las palabras que se baten en retirada. La mayor parte de las veces convergen los motivos positivos y negativos en una acción común.

De esta manera ha ocurrido por ej. que el francés antiguo designa al "conejo" como "connil" o "connin", y que "lapin" no aparece por vez primera sino en el siglo XVI; así las cosas, la expansión de este último vocablo a costa de la decadencia de los dos primeros se debe a un motivo negativo para ellos dos: se los percibió en la lengua coloquial en tanto derivados de "cunnus" o se los asoció a esta palabra, por lo que se perdieron las dos voces francesas vitandas por su obscenidad (Ibid., cap. IV).

5. "Que el estudio de las fronteras fonéticas puede dar mucha luz sobre las relaciones mutuas entre historia y lengua es algo que ha demostrado Gauchat de una manera convincente y mejor que ningún otro romanista" (Ibid., p. 84).

Del bello libro -son unas conferencias, como el anterior (las presentes, de 1933)- Aspects géographiques du langage, recogemos lo que resulta doctrinalmente esencial.
Explica Jaberg cómo con su Atlas hecho en colaboración (el "AIS"; sobre él vid. Pop, 1951, pp. 560-597; lordan, 1967, pp. 426-432), los autores han deseado y buscado alcanzar un progreso en "biología del lenguaje", "sociología lingüística", y relaciones o vinculaciones entre palabras y cosas, y advierte cómo ya a Gilliéron le preocuparon las dos primeras de estas cosas: respectivamente, lucha entre elementos tradicionales y elementos novedosos del lenguaje; vitalidad de los "patois"; etc.

De esta manera se vuelve preciso encuestar a hablantes de edades diferentes y de distintas clases sociales, y de los dos sexos; asimismo "on ne peut pas faire l'histoire des mots sans faire l'histoire des choses", aunque este enunciado pueda parecer a primera vista -expresa el propio autor- una banalidad (Jaberg, 1936, pp. 19-28).

A mitad de los años cincuenta de su centuria, sabido es cómo Jaberg se manifestó acerca de los Atlas llamados de "grandes" o de "pequeños" dominios en un trabajo postrero; su experiencia le condujo -hace la presente estimación lordan- al convencimiento que el análisis geográfico-lingüístico "puede realizarse mejor con ayuda de los atlas regionales, es decir, limitados a territorios reducidos" (1967, pp. 363-364).

En estas páginas a las que aludimos los denomina respectivamente "atlas nacional" o "atlas del país" y "atlas regionales". El atlas nacional -recordamos cómo lo define el autor- es 'la proyección cartográfica de las peculiaridades dialectales de un país [..., ] proyección que normalmente abarca los dominios pertenecientes a la misma lengua común', por lo que se fundamenta en el registro de algunos hechos lingüísticos tal como aparecen en los puntos de encuesta que han sido seleccionados previamente.

Se trata de esta manera de llegar a conocer "la macroestructura lingüística de un país", o lo que es lo mismo, "la fragmentación de un gran espacio lingüístico en regiones dialectales" relativamente uniformes. Esta técnica cartográfica -apostilla además Jaberg- se hizo estudio científico cuando se empezaron a poner en relación los límites dialectales que se dibujaban en los mapas, "con las fronteras topográficas, políticas, culturales e históricas" (Jaberg, 1995, pp. 15-16; cfr. Iordan, 1967, pp. 350-359, etc.).

De su lado el atlas regional consiste en 'la representación cartográfica de un dominio dialectal [...] que se diferencia de los dialectos vecinos por la combinación [entiéndase: 'por una suma'] de propiedades lingüísticas típicas', de manera que a este atlas más pequeño le cabe recoger "las más finas variantes dialectales", dado que la red de puntos de encuesta resulta en su caso más densa o espesa (Jaberg, 1995, p. 17).

De cualquier manera -establece asimismo nuestro autor-, a los atlas pequeños corresponde reflejar la microestructura fonética regional y local, a los dialectólogos interpretarla desde los puntos de vista histórico-fonético, geográfico, "histórico y sociológico", mientras el atlas nacio- 
nal permite establecer dependencias en función de la historia y poner de manifiesto "la dinámica de la macroestructura fonética" (lbid., p. 54).

Vàrvaro glosa cómo en efecto el Atlas nacional resulta "más adecuado para servir de base a un estudio histórico de la lengua", mientras el regional permite comprobar la "biología y economía lingüisticas" (Vàrvaro, p. 169).

\section{Un comentarista de Jaberg}

Entre otros sucesivos filólogos, ha sido Pierre Swiggers (2004-2005; vid. también las páginas que alli se citan de Hilty) quien glosaba no hace muchos años la obra de Jaberg, y quien de esta manera sostenía:

a) En alguna medida y de acuerdo con el propio $G$. Hilty, K. Jaberg "ha sido un sociolingüista avant la lettre".

b) Los dialectos son menos "homogènes" que las lenguas, de manera que los dialectos "sont des langues généralement "labiles"".

c) La geografía lingüistica "vise essentiellement à éclairer l'interdépendance externe des [...] systèmes langagiers. [... et] se propose d'expliquer comment les états linguistiques actuels ont pu survenir".

d) La dialectología la entiende también Jaberg de manera complementaria, en tanto el estudio de un espacio -pensemos por ej. el andaluz-, espacio en cuyo interior se trata de ver "les centres de renouvellement, la propagation et les tendances des faits linguistiques, aussi que les conditions qui les déterminent".

e) A la vista de la lengua como hecho social, tarea del lingüista será la "d'expliquer la propagation des changements linguistiques, c'est à dire, d'en rechercher los conditions qui déterminent si une innovation se généralise".

f) Jaberg insiste en el anterior concepto schuchardtiano de "Sprachmischung" o 'mezcla' que tenemos visto: "celle-ci pénètre la réalité linguistique dans son intégralité".

En fin y según varios comentaristas a los que nos sumamos, la obra de Karl Jaberg resulta insuficientemente conocida.

\section{El modelo dialectal-sociolingüístico}

Los estudios geográfico-lingüísticos han quedado con el tiempo unidos a los sociolingüísticos, a lo que se han llamado "dialectos verticales", o sea, a las diferenciaciones en el hablar según la diastratía de la mayor o menor instrucción de los hablantes.
Aunque respecto de la lengua española fue José Pedro Rona acaso quien planteó un primer programa de análisis diastrático y fue este estudioso quien incidió primeramente en otros autores, los trabajos iniciales de William Labov por igual dejaron su huella en dialectólogos del mundo hispánico que los mencionan de manera expresa. Varios de esos estudios primeros de Labov se hallan reunidos en el volumen que en castellano se rotula como Modelos sociolingüísticos; estamos ante un paradigma de estudios del que debe tenerse una idea general.

Labov manifiesta al frente de estas páginas suyas cómo "la vida cotidiana es dura pero también coherente, [...] confunde de entrada pero recompensa a la larga a quienes se aferran a su carácter racional" (Labor, 1983, p. 23); las presentes palabras están enunciadas con carácter general, pero aplicadas a lo lingüístico sugieren que los usos idiomáticos del hablar diario no resultan irregulares o caóticos por algunos de sus rasgos, sino que tales rasgos responden a una racionalidad: edad del hablante, pertenencia sociocultural, etc. La vida es racional, es lógica, aun en su irracionalidad (lo irracional puede explicarse racionalmente), y en concreto el hablar posee asimismo una racionalidad social.

En el hablar existen "variantes subfuncionales" (Labov 1983, p. 167) que no resultan pertinentes para entenderse, pero que pueden responder a la estratificación del idioma: lo funcional es lo pertinente, pero hay un algo más que puede consistir en mero polimorfismo indiferente, mas asimismo puede responder a hábitos vinculados al nivel sociocultural al que pertenezca el hablante: lo llamado subfuncional no es pertinente desde el punto de vista del éxito comunicativo, pero sí puede resultar sintomático sociológicamente: la neutralización de las vocales átonas (despertar / dispertar) no entorpece la comprensión del mensaje porque es subfuncional, pero indica un nivel sociocultural más bajo.

El sociolingüista Labov diseñó una vez un esquema ideal del que llama mecanismo del cambio lingüístico, y enumeró entonces entre otros hechos:

1. "Los cambios fonéticos se originan frecuentemente en un subgrupo restringido de la comunidad lingüística" (Labov, 1983, pp. 229-233 para todo esto de que nos hacemos eco simplificadamente).

2. "Los cambios comienzan como generalizaciones de la forma lingüística a todos los miembros del subgrupo", lo que constituye un cambio desde abajo.

3. "Sucesivas generaciones del mismo subgrupo, sometidas siempre a las mismas presiones sociales, continúan el mismo proceso."

4. "En la medida en que los valores del subgrupo original son adoptados por otros grupos de la comunidad, el cambio fonético que es un valor asociado a la 
pertenencia de grupo, pasa igualmente a los grupos que lo adoptan. La función de pertenencia de grupo se redefine en cada nueva etapa."

5. , y de importancia: "Los límites de la difusión del cambio fonético coinciden con los de la comunidad lingüistica, definida como un grupo que comparte un conjunto de valores normativos respecto al lenguaje."

6. "En la medida en que el cambio fonético y sus valores asociados alcanzan los límites de su expansión, la variable lingüistica se convierte en una de las normas que definen la comunidad de habla, y todos los miembros de dicha comunidad reaccionan de manera uniforme a su uso."

7. "Si el grupo en el que el cambio se origina no es el de estatus más alto en la comunidad lingüística, los miembros de mayor estatus puede relegar esta forma que ha cambiado mediante el control que ejercen sobre las diversas instituciones de la red de comunicaciones."

8. , y asimismo importante: "Si el cambio se origina en el grupo de mayor estatus, este se convierte en modelo de prestigio para todos los miembros de la comunidad. La forma modificada es adoptada entonces en los modos de discurso más cuidados por otros grupos en la medida en que mantienen contactos con los usuarios de dicho modelo de prestigio, y en menor medida es adoptada también en el discurso casual."

La conclusión que se desprende de esta figuración ideal es que ningún sistema idiomático que cambia es un sistema autónomo, inmanente: si la lengua vive en un medio social e histórico, resulta naturalmente penetrada por lo histórico y lo social.

Menéndez Pidal propuso un modelo del cambio lingüistico sensato y acertado, cuando aún no se habian iniciado los estudios sociolingüísticos específicos, ya en un escrito de 1944 sobre la unidad del idioma; luego Labov lo ha postulado con mayor detalle y finura, pero en esencia resulta compatible y coherente con el pidalino.

En todo caso y en general, William Labov ha repetido varias veces la importancia empírica que posee para los estudios sobre el lenguaje un examen real de las condiciones y los productos del hablar, a saber: "si queremos aprehender el lenguaje tenemos que examinar los datos del habla cotidiana lo más detallada y directamente posible" (Labov 1983, p. 256); de esta manera y provistos de tal riqueza empírica, habrá de corregirse la teoría para ajustarla a los hechos con adecuación material y formal o intelectiva.

Dice nuestro autor que resulta una paradoja que "cuanto más se sabe de una lengua, más se puede descubrir de ella" ( $p$. 257), más cabe descubrir, y esto deberá entenderse: estamos -nos parece- ante una paradoja aparente, pues en realidad al conocer mejor los mecanismos del hablar descubrimos de manera mejor todos sus componentes y las complejidades que presenta, y esto lleva a buscar más, a indagar más y conocer más. Un objeto mejor analizado produce más resultados en el conocimiento, y ese conocimiento llama a más conocimiento; si enfocamos no ya y sólo un hablante-oyente ideal ('idealizado, no empírico'), sino un hablante real condicionado por su situación geográfico-sociológica, estaremos más cerca de describir con mayor contenido el lenguaje en sus manifestaciones concretas, y no lo reduciremos simplificándolo.

El designio proclamado por Labov respecto al idioma es el de ajustarse de la manera más exacta posible a su consistencia empírica, que es desde luego -cabe añadir de manera expresa- escindida o dialectalizada interiormente; sin embargo vemos que "está nuestra tendencia habitual a aceptar ideas que se ajustan a nuestro marco de referencia sin darnos cuenta de los datos que nos rodean" (Labov, 1983, p. 259). Un marco de referencia resulta imprescindible para saber qué se busca y qué se quiere encontrar, pero ese marco de referencia habrá de ajustarse y reajustarse a lo real si quiere ser empíricamente adecuado; luego vendrá la adecuación explicativa, el tratar de explicar la realidad considerada, pero antes tenemos que habérnoslas con una realidad que no se halle simplificada y mutilada.

"La teoría lingüística - proclama nuestro autor- no puede seguir ignorando la conducta social de los hablantes de una lengua" (1983, p. 324), esto es, lo que por razones de estructuración y estratificación sociales Ilevan en sí los enunciados, su configuración condicionada. Mirando hacia atrás William Labov encuentra que los lingüistas se dividen en dos grandes tendencias o grupos:

El Grupo A, el grupo "social", presta una atención estricta a los factores sociales para explicar el cambio [lingüistico...] y pone el énfasis en la importancia de la diversidad lingüística. [...] Los lingüistas del Grupo B, el grupo "asocial", centran su atención en los factores puramente internos estructurales [... y] toman la comunidad lingüística homogénea, monolingüe ['uniforme'] como su objeto propio (Labov, 1983, p. 330).

La homogeneidad de una comunidad lingüística, su "monolingüismo" (entiéndase que su consideración simplificada) no se corresponde con lo real; los factores del lenguaje son por supuesto estructurales e internos, inmanentes, pero a la vez y conjuntamente otros hechos que inciden en el mecanismo del idioma son los externos socioculturales. Nuestro autor adscribe a este Grupo A de autores a por ej. Schuchardt, Meillet, o Jespersen; del Grupo B forman parte Martinet o Chomsky (1983, p. 332).

Aunque la dialectalidad interior del idioma se da incluso en el seno de una misma familia, en uno de llamados "microcosmos" lingüísticos aunque sea pequeño, etc., una 
lengua tan extendida como la española ha de presentar -por esa gran difusión- una enorme dialectalidad y complejidad: dialectos propiamente dichos; diglosia; sesquilingüismo [ 'el hablante se expresa en una lengua pero entiende además otra, posee bilingüismo receptivo o pasivo']; criollos; ...

\section{La desigualdad social en el espejo de la lengua: sociología de lo dialectal}

José Pedro Rona estableció que "cada fenómeno comprobado en el habla de determinada capa socio-cultural [...] en comparación con los fenómenos de otras capas socioculturales del mismo lugar, [tiene una diferencia] de nivel", y de esta manera "el valor de un fenómeno debe determinarse en relación con los otros niveles de la misma comunidad hablante" (Rona, 1958, p. 14); estamos por tanto ante "isoglosas entre las distintas capas sociales" (lbid., p. 15). Con posterioridad el propio Rona llevó a cabo una nueva conceptuación acerca de en qué debia consistir el análisis sociolingüístico, y entonces matuvo:

a) la sociolingüística especificamente lingüística estudia "la estratificación interna" de una lengua con sus dialectos; "la comparación de diferentes estratos [...] será la finalidad de la lingüística diastrática".

b) "la diferenciación diastrática es muy similar a la diatópica (dialectal)".

c) Dicho de otra manera: "Una descripción [de la estratificación interna] será la descripción de cierto estrato socio-cultural, diferente de los otros estratos existentes en la misma área y el mismo periodo. La comparación de estratos diferentes existentes en la misma área suministrará un conocimiento que puede ser comparado a la dialectología" (Rona, 1970, pp. 204-206; 212). Debe entenderse que este autor emplea aquí la voz dialectología en el sentido más limitado de 'análisis diatópico o geográfico', pues con un significado más amplio la misma palabra puede designar asimismo el análisis diastrático o sociológico-vertical.

d) "Deberia siempre haber [una teoria ...] que tendría que preceder al método, ser una verdadera teoría del método. Esta teoría del método es diferente de la teoría del objeto de la ciencia, que no puede alcanzarse sino después de haberse reunido los datos pertinentes" (Rona, 1970, p. 211). Se trata pues de que hay evidentemente una teoría del objeto, que en este caso es la teoría lingüística, y una teoría del método, de cómo ha de hacerse el análisis: si no se tiene concebido que se va a estudiar la diferenciación idiomática, no podrá hacerse bien la selección de informantes para la encuesta. En la investigación no se puede encontrar un resultado si no está planteado de antemano qué es lo que buscamos: la estrategia de un análisis literario que estudie la historia de las mentalidades será distinta de la de un análisis formal-elocutivo; en lingüística una encuesta diatópica no puede planearse exactamente igual que una sociolingüística, etc.

Estas páginas del autor uruguayo se tomaron un poco en tanto un bien común, mostresco, y de esta manera no siempre se las menciona.

En un momento posterior al primer escrito mencionado de J. P. Rona, Manuel Alvar llevó a cabo algunas consideraciones de doctrina; en realidad se apoya en Karl Jaberg -a quien menciona-, el cual ciertamente en un texto suyo de relieve había postulado (según hemos visto) la necesidad de atender a lo sociológico en el lenguaje: Jaberg tenía escrito que hay que informarse acerca de "les parlers socialment inférieurs"; que ha de atenderse a informantes dialectales "d'âges différents et appartenant à différents classes sociales"; y que en definitiva han de tenerse presentes "les divergences linguistiques résultant de couches sociales, de sexes et d'âges différents" (Jaberg, 1936, pp. 19-22 -ya aludidas-). Alvar pide -en esa línea- que ciertamente haya atención a lo dialectal geográfico, pero asimismo a lo diastrático sociológico: "Un hablante, por pertenecer a un nivel determinado (campesino, obrero, intelectual, etc.), ya nos está dando materiales sociológicos; al mismo tiempo que por hablar según las normas que rigen en un determinado sitio nos facilita materiales geográficos"; en definitiva ocurre cómo la sociología lingüística "es necesaria para una apurada visión de los hechos dialectales" (1968, pp. 27 y 35$)$.

En relación específica al dialecto canario, nuestro estudioso proclamaba: "Tenemos que estudiar sus distintos niveles sociales y los distintos grupos que integran cada uno de esos niveles o que participan de varios de ellos" (1968, p. 31), o sea, que geografía y sociología resultan componentes del hablar y por tanto han de resultarlo de su descripción: "será necesario el estudio de los distintos estratos sociales para conocer los "dialectos verticales" [...], pero será necesario conocer -también- la difusión geográfica de los fenómenos", pues es cierta "la existencia de niveles socio-culturales" en las Islas (Ibid., pp. 32-33). 


\section{BIBLIOGRAFÍA}

AlCALÁ-ZAMORA Y QueIPO dE LLANO, José (1970): "La monarquia hispana de los Felipes", RUM, 73, pp. 57-106.

Artículo-resumen de las investigaciones hasta entonces de su autor quien en coherencia se ha ocupado asimismo de Calderón (a quien tiene por "nuestro máximo dramaturgo"). En las páginas presente proclama "el interés inagotable y siempre renovado de nuestra Edad de Oro, ese tiempo "superior a la especie humana" en que el Gran Espíritu de la Historia, por remedar a Hegel, sobrevoló el meridiano español", así como -y este enunciado resulta muy sugestivo- "la evidencia de ser la quiebra española del siglo XVII la que imprime un fuerte ángulo de deriva a la trayectoria histórica posterior hasta nuestros días de los pueblos ibéricos, condicionándola hasta unos limites de profundidad muy poco averiguados todavia".

- 1975: España, Flandes y el Mar del Norte (1618-1939). La última ofensiva europea de los Austrias madrileños, Barcelona, Planeta.

Planteamiento en el que se entremezclan lo geográfico y lo histórico, una muestra de monografia geohistórica.

AluIX, André (19603): Manual de Geografía General. Física, Humana y Económica, Madrid, Rialp.

Manual clásico, de referencia en las Facultades de Filosofía y Letras españolas en los años cincuenta y parte de los sesenta del siglo pasado. Allix fue uno de los maestros del medievalista de relieve Georges Duby.

AlvaR, Manuel (1968): Estudios Canarios, I, Cabildo Insular de Gran Canaria.

Agrupación de páginas en torno a las hablas canarias; tras Rona y D. Catalán, se postula la unión del análisis diatópico con el diastrático.

Braudel, Fernand (1968): La Historia y las ciencias sociales, Madrid, Alianza. Una primera y bella reunión en castellano de escritos de método del autor.

- 1976²: El Mediterráneo y el mundo mediterráneo en la época de Felipe II, Madrid, FCE.

Obra magna considerada como un verdadero texto de Geohistoria, su autor llevó a cabo aún otras obras señeras, todas las cuales son imprescindibles para los varios asuntos de su compleja temática respectiva (el capitalismo; Francia).

Braudel se confiesa alumno de los textos de Marc Bloch, y del estímulo de Lucien Febvre.

Comellas, José Luis (2011): Historia de los cambios climáticos, Madrid, Rialp.

Exposición de conjunto en la que un historiador monográfico del Ochocientos español, aúna sus conocimientos astronómicos e historiográficos. De utilidad instructiva.

El gran defensor actual de las relaciones clima-historia a mitad del Seiscientos es ahora G. Parker, de quien hemos alcanzado a ser alumnos.

CoserIU, Eugenio (1977): El hombre y su lenguaje, Madrid, Gredos. Preciosa reunión de artículos, tan inteligente y sugestiva como cualquier cosa de su autor.

DUBY, Georges (1992): La historia continúa, Madrid, Debate. Autobiografía intelectual de un medievalista eminente, desaparecido pronto.

FeBVRE, Luciano (1925): La tierra y la evolución humana, Barcelona, Cervantes.

Panorama de cuestiones geográficas, introductorio para una amplia Historia universal. Escrito en colaboración, y traducido por un joven Luis Pericot.

FeBVRE, Lucien (1970): Combates por la Historia, Barcelona, Ariel. Edición parcial de algunos textos de relieve de este gran autor. Necesario.

- (1982): Pour une Histoire à part entiére. Otra recopilación indispensable de textos suyos.
IORDAN, lorgu (1967): Lingüistica Románica. Evolución, corrientes, métodos, Madrid, Alcalá.

Exposición de lo que anuncia el subtítulo, a veces un tanto vaga e inconcreta.

JABERG, Karl (1936): Aspects géographiques du langage, Paris, Droz. Obra de gran interés entre las de su autor y entre las que se ocupan de la materia.

- 1959: Geografía lingüistica. Ensayo de interpretación del "Atlas Lingüistico de Francia", Universidad de Granada. Análisis y comentarios acerca del "ALF".

- 1995: Estudios de geolingüistica; Universidad de Granada El estudio fundamental del autor acerca de los Atlas de pequeños dominios.

LABOV, William (1983): Modelos sociolingüisticos, Madrid, Cátedra. Texto seminal que reúne contribuciones algunas de las cuales fueron conocidas concreta o difusamente, y de manera temprana, por los estudiosos del español.

Menéndez PIDAL, Ramón (1933): "El lenguaje del siglo XVI", Cruz y Raya, 6, 15 de Septiembre, pp. 7-63.

Esbozo inicial de una Historia de la lengua española que el autor escribió, aunque redactando de nuevo lo ya escrito en referencia al Quinientos.

- 1962 [1906]: El dialecto leonés, Oviedo, IEA. Reedición con añadidos a cargo de C. Bobes de un texto importante.

- 2005: Historia de la lengua española, I y II, Madrid, Fundación Ramón Menéndez Pidal y RAE.

Edición póstuma de originales del autor escritos en su mayor parte durante la guerra española y la II guerra mundial. Obra fundamental y necesaria entre las publicadas por la filología española de toda la centuria del XX.

PoP, Sever (1951): La Dialectologie. I. Dialectologie romane, Gembloux, Imprimerie J. Duculot.

Obra fundamental para la fecha de su publicación y de necesaria consulta, de gran empuje y que debe agradecerse al autor.

RonA, José Pedro (1958): Algunos aspectos metodológicos de la dialectología hispanoamericana, Montevideo, Universidad de la República.

Artículo rara vez citado, pero que ha incidido en las investigaciones dialectales diastráticas que empezaron a hacerse aplicadas a la lengua española. Enlaza con la preocupaciones teóricas sobre la lengua en América de Amado Alonso; vigente a más de medio siglo de su publicación.

- 1970: "La concepción estructural de la Sociolingüistica", en GarvinLastra, eds., pp. 203-216.

Artículo de importancia y -en parte- seminal.

SWIGgerS, Pierre (2004-2005): "La linguistique de Karl Jaberg: La géographie linguistique nourrie par la sociologie et la psychologie du langage", Dacoromania, 19, pp. 29-44

TAMAMES, Ramón (1969): Estructura Económica de España, Madrid, Guadiana.

VÀrVAro, Alberto (1988): Historia, problemas y métodos de la lingüística románica, Barcelona, Sirmio.

Velarde Fuertes, Juan y Campos Nordmann, Ramiro (19692), Lecciones de Estructura e Instituciones económicas de España, Madrid, SMAR Artes Gráficas.

VENDRYES, J (1979): El lenguaje. Introducción lingüística a la historia, México, UTEHA.

Obra general e introductoria, de importancia en su momento (años veinte).

VICENS VIVES, J. (1950a): Tratado general de Geopolitica, Universidad de Barcelona y Ed. Teide.

Obra de conjunto sobre la materia, que responde a algunas de las preocupaciones del autor por entonces. Esta actividad vicentina la refiere quien fue su colaborador Joaquín Bosque Maurel en uno de los artículos recogidos en su Geografía y geógrafos en la España contemporánea (Univ. de Granada, 1992 -pp. 66-67-); no la registra 
Juan Vilá Valentí en El conocimiento geográfico de España. Geógrafos y obras geográficas (Madrid, Sintesis, 1989).

Vicens Vives, J. y Bosque MaureL, J. (1950b): Las potencias mundiales, Barcelona, Teide.

Manual de Bachillerato bien hecho. La colaboración de Bosque debió de surgir en la estancia de Vicens en su primera cátedra za- ragozana; desconocemos en qué consistió ahora esa colaboración, pues lo escrito por Vicens se detecta muchas veces, dado que Jaume Vicens lo utilizó en otros textos suyos.

VICENS-BOSQUe-WagneR (1956): Universo. Tierra, productos y Estados, Barcelona, Teide. La parte de geopolitica -con referencias geohistóricas- está escrita por el propio Jaume Vicens. 